\title{
Um olhar francês sobre a música popular brasileira
}

\author{
[ A French look at Brazilian popular music
}

\section{Flavia Rejane Prando ${ }^{\mathrm{I}}$}

[FLÉCHT, Anaïs. Madureira chorou... em Paris: a música popular brasileira na França do século XX. São Paulo: Edusp, 2017.

RESUMO - Os ritmos do Brasil tornaram-se populares na sociedade francesa e ditaram tendências musicais palpáveis durante o século $\mathrm{XX}$. Como essas músicas brasileiras chegaram à França e o que sua recepção nos diz acerca da sociedade na época? Que práticas rítmicas e instrumentais foram adotadas, adaptadas e absorvidas por músicos franceses? Esses são alguns questionamentos tratados na pesquisa que analisa a difusão e o impacto da música brasileira na França. Trata-se de uma publicação que vem enriquecer a bibliografia nacional, apresentando uma história original da recepção musical fora do Brasil, lançando novas luzes sobre a história transcultural da música brasileira. •PALAVRAS-CHAVE - Música brasileira; Brasil-França; maxixe; samba. •

\begin{abstract}
The rhythms of Brazil became popular in French society and dictated some musical trends through the twentieth century. How did these Brazilian songs come to France and what do their reception tell us about the French society at that time? Which rhythmic and instrumental practices were adopted, adapted and absorbed by French musicians? These are some questions that the research analyzes about the diffusion and the impact of Brazilian music in France. It is a publication that enriches the national bibliography, presenting an original story of the musical reception outside of Brazil, shedding new light on the transcultural history of Brazilian music. - KEYWORDS - Brazilian music; Brazil-France; maxixe; samba.
\end{abstract}

Recebido em 4 de abril de 2018

Aprovado em 9 de novembro de 2018

PRANDO, Flavia Rejane. Um olhar francês sobre a música popular brasileira. Revista do Instituto de Estudos Brasileiros, Brasil, n. 7I, p. 292-302, dez. 2018.

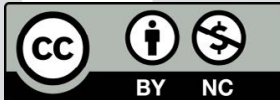

DOI: http://dx.doi.org/Io.II6o6/issn.23I6-90IX.voi7Ip292-302

I Universidade de São Paulo (USP, São Paulo, SP, Brasil). 


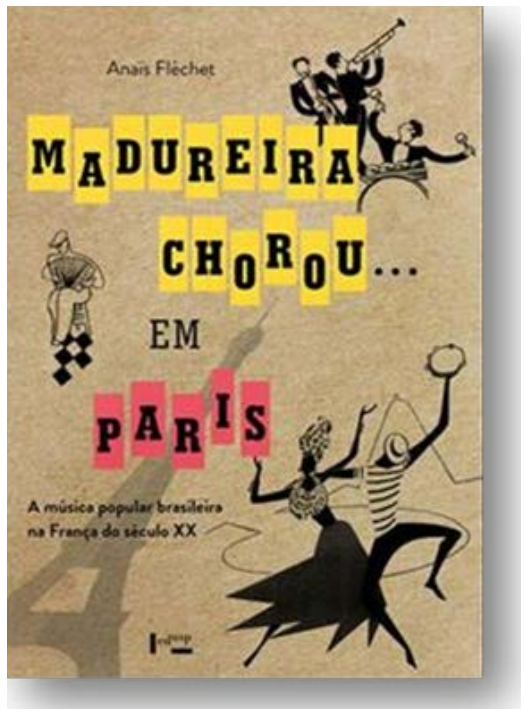

Traduzida para o português com o título Madureira chorou... em Paris: a música popular brasileira na França do século XX, a publicação consiste em uma adaptação da tese de doutorado em história (2007) de Anaïs Fléchet ${ }^{2}$, intitulada "Si tu vas à Rio...". La musique populaire brésilienne en France au $\mathrm{XX}^{e}$ siècle, publicada em livro na França, em 20I3, pela editora Armand Colin. A edição brasileira foi feita pela Edusp (20I7) com o apoio do Instituto Francês do Brasil. "Si tu vas à Rio" é o nome que o samba "Madureira chorou" (I958), de autoria dos compositores Carvalhinho e Júlio Monteiro3, recebeu na língua francesa, música que fez sucesso na França na década de I950, na interpretação do cantor turco Dario Moreno (I92I-I968). O livro conta com a apresentação de Marcos Napolitano, professor do Departamento de História da Faculdade de Filosofia, Letras e Ciências Humanas (FFLCH) da USP. Na orelha e contracapa do livro, o historiador ressalta que, apesar da circulação internacional de alguns músicos brasileiros - de Pixinguinha nos anos I920 à trajetória de músicos como Gilberto Gil, Caetano Veloso e Chico Buarque na segunda metade do século XX - ser bastante conhecida

2 Anaïs Fléchet é professora de história na Universidade de Versailles Saint-Quentin-en-Yvelines, mestre e doutora em história das relações internacionais da Universidade Paris I Panthéon-Sorbonne, e pesquisadora do Centre d'Histoire Culturelle des Sociétés Contemporaines. É autora de Villa-Lobos à Paris. Un écho musical du Brésil (Paris: L'Harmattan, 2004) e editora de Une histoire des festivals XXe-XXIe siècles (Paris: Publications de la Sorbonne, 20I3), Villa-Lobos. Des sources de l'oeuvre aux échos contemporains (Paris, Honoré Champion, 20I2) e Musique et relations internationales, número duplo da revista Relations Internationales (Paris/Genève, $\mathrm{n}$. I55-I56 automne 20I3-printemps 20I4).

3 A música pode ser ouvida na versão original em: <goo.gl/ZwgjUJ>, e na adaptação francesa em: <goo.gl/ cdDPbZ>. Acesso em: 30 jan. 2018. 
e estudada, nenhum pesquisador havia reunido esses momentos em um só livro. Destaca ainda que a autora, ao incorporar ao estudo a influência de outro eixo do mercado musical internacional a partir dos anos I930, os Estados Unidos, apresenta uma história transnacional da música brasileira. Nota, ainda, a impressionante massa documental que a autora mobiliza para recompor o histórico da circulação de artistas e canções brasileiras ao longo do século XX na França. Nesse arco histórico, Napolitano enfatiza as concepções plurais dos franceses sobre a música do Brasil, indo do consumo exótico à celebração do moderno.

A autora apresenta amplo conhecimento dos processos históricos e sociais envolvidos no desenvolvimento da música brasileira, o que possibilita a realização de um cotejamento efetivo entre a produção musical brasileira e a sua recepção e produção na França, focos mais específicos de sua análise nesse trabalho. Mais do que uma história da recepção da música brasileira na França, o livro trata das transferências culturais entre Brasil e França; da consolidação dos gêneros musicais brasileiros; da emergência de uma cultura musical de massa impulsionada pelos novos vetores de difusão; da legitimação progressiva dos ritmos afro-brasileiros e de outras influências envolvidas nesses processos, notadamente a presença norte-americana.

Entre as perguntas que guiam o livro, podemos elencar: quais foram as modalidades de difusão e de apropriação da música brasileira ao longo do intenso intercâmbio entre as duas margens do Atlântico? Qual foi o teor do "novo mundo sonoro" revelado aos franceses? O que esse fenômeno permite conhecer sobre os imaginários, as tensões e os desejos que percorriam a sociedade francesa?

Para a construção da pesquisa, a autora utiliza-se de um espantoso número de fontes, com as quais tece uma história das apropriações e trânsitos culturais que abrange ao mesmo tempo uma análise das práticas musicais, uma sociologia das mediações e um estudo dos discursos imaginários. Entre as fontes consultadas, brasileiras, francesas e norte-americanas, citamos: catálogos de bibliotecas e arquivos sonoros, fontes audiovisuais, partituras e programas de concertos; contratos e correspondências privadas de músicos; arquivos diplomáticos; guias, atlas e relatos de viagens; manuais de dança e métodos destinados a músicos. Entre as fontes orais, destacamos: depoimentos de músicos brasileiros; entrevistas realizadas pela autora com músicos, produtores e jornalistas musicais, franceses e brasileiros, entre $2002 \mathrm{e}$ 2006, sendo que as mais significativas, segundo a autora, constam no livro4.

O inventário dos variados documentos de diversos acervos dos três países é, em si, inédito para a bibliografia musical brasileira. Entre os acervos consultados pela autora estão: Fonoteca Nacional e Departamento Audiovisual da Biblioteca Nacional da França (BNF); Divisão de Música da Fundação Biblioteca Nacional (FBN) e do Instituto Moreira Salles no Rio de Janeiro, assim como os arquivos da Universidade de Santa Bárbara, da Biblioteca do Congresso Norte-Americano e o index da Encyclopedic Discography of Victor Recordings; Coleções do Departamento de Música da BNF; FBN; Ministério das Relações Exteriores em Brasília e Museu

4 São oito as entrevistas constantes no livro, a saber: Caetano Veloso, Pierre Barouh, Chico Buarque de Holanda, Georges Moustaki, Violeta Arraes Gervaiseau, Carmélia Alves, Françoise Hardy e Rémy Kolpa-Kopoul. 
da Imagem e do Som (MIS) do Rio de Janeiro. Além disso, ressalta-se que o grande arco temporal abordado no livro, analisado de maneira integrada em uma narrativa coerente, que possibilita a recomposição das mediações, das influências e dos conflitos culturais envolvidos na difusão da música brasileira em circuitos internacionais, é inédito na historiografia musical brasileira.

As fontes acima citadas são bem manejadas e servem de ponto de partida para desmistificar a ideia da relação cultural em sentido único, do centro para a periferia, ou, no caso, da Europa para as Américas, para atestar a reciprocidade das transferências culturais entre os dois países. Para trabalhar a questão das transferências culturais, a pesquisadora utiliza-se de autores como Michel Espagne e Michel Werner, enquanto evoca Roger Chartier para tratar da história das apropriações. As questões de centro-periferia são baseadas em autores como Serge Gruzinski e Philippe Minard, que tratam do desenvolvimento do debate transnacional nas ciências históricas, e em autores como Anne Dulphy para a trajetória das relações culturais internacionais.

A autora justifica a necessidade do cruzamento de tantas fontes pela dificuldade encontrada em estabelecer um corpus substancioso para a pesquisa. Isso porque o trabalho retrata um período longo, porém não contínuo, tampouco uniforme. Houve períodos de recuo na difusão e na produção da música brasileira na França que ocasionaram a descontinuidade de muitas das fontes. Outro fator apontado é que os fonogramas só foram submetidos ao depósito legal 5 depois da criação da Fonoteca Nacional (I938). Além disso, havia ainda a política de silêncio imposta pelas sociedades de direitos autorais, que não se interessavam em pagar esses direitos aos compositores e herdeiros. Fléchet nota que ainda hoje a Société des Auteurs, Compositeurs et Éditeurs de Musique (Sacem) "é sem dúvida o melhor exemplo dessa política de recusa sistemática que se opõe aos pesquisadores” (p. 28). A fim de evidenciar a geografia das transferências culturais, a autora faz uso de gráficos que cruzam a produção de discos, partituras e programas de rádio, possibilitando uma melhor compreensão da presença da música brasileira na paisagem sonora francesa. Esses gráficos e as avaliações numéricas que ilustram o livro servem para medir a amplitude relativa da música brasileira comparada com o restante da produção musical na França e auxiliam na visualização do desenvolvimento dessa produção ao longo do século XX, além de evidenciar os períodos em que os diversos gêneros brasileiros avançam e recuam em sua difusão ao longo do século XX.

Frente a realidades tão diversas apresentadas pelos dois países, aos distintos períodos históricos abordados e à multiplicidade de fontes, surge a pergunta: como abarcar a complexidade das circulações culturais sem perder de vista as relações de força e as hegemonias que elas refletem? Para dar conta da tarefa, a autora divide a obra em três partes, cronológicas, onde discute a trajetória das circulações dos dois lados do atlântico, trazendo à margem o que as transferências culturais representaram dentro do contexto de cada país. Cada uma das três partes do livro - Revelação de um Novo Mundo Sonoro: I905-I940; O Sonho Exótico: I945-I959; e

5 O depósito legal é a obrigação legal feita a qualquer editor de livros ou publicações de enviar um ou mais exemplares de qualquer obra impressa no país a um repositório específico, geralmente sua biblioteca nacional. 
Brasil, Nouvelle Vague (I960-2000) - é dividida em três capítulos e precedida de uma introdução na qual a autora apresenta um panorama da vida musical e cultural de cada período abordado nos dois lados do Atlântico.

O gosto dos outros, em referência ao livro homônimo de Benoît de L'Estoile (2007), fundamental aos interessados nas relações entre a antropologia e os museus etnográficos, e, que, segundo a autora, "qualifica as diversas formas de apropriação das 'coisas dos outros', entendidas em um sentido amplo de manifestações de alteridade cultural" (p. 38), serve de pano de fundo para as três fases. Esse gosto dos outros sofre transformações ao longo do século XX, e a autora o classifica em cada uma das fases como primitivo, típico e autêntico, respectivamente, evidenciando um desenvolvimento do gosto dos franceses pela música brasileira.

O primitivo corresponde ao período da primeira metade do século XX, focalizado na ideia do selvagem, em oposição à civilização europeia - as geografias são fantasiosas e se reduzem ao Rio de Janeiro, as paisagens frequentemente são associadas aos pampas argentinos, ressaltam-se os ritmos do caribe e latino-americanos ao Brasil na moda das danças exóticas, como os tangos e habaneras desse primeiro período. $\mathrm{Na}$ primeira parte do livro, Revelação de um Novo Mundo Sonoro (I905-I940), a autora trata do período da belle époque até o advento da Segunda Guerra Mundial. Nas duas primeiras décadas do século XX, o público francês descobriu a música brasileira em duas modalidades: a moda das danças exóticas abriu caminho primeiramente para o maxixe e depois para o samba, e a onda do primitivismo, gerada pelo Modernismo, gerou um interesse pelas músicas negras e indígenas do Brasil, tanto nos salões quanto nas publicações eruditas.

Fléchet evidencia como aconteceram os intercâmbios entre artistas, mecenas e empresários. Desnuda uma rede de agentes privados e mediadores que é o eixo das relações entre Brasil e França até a década de I930. Entre os músicos destacam-se Heitor Villa-Lobos (I887-I959), Darius Milhaud (I892-I974) e o compositor paulista de maxixes e sambas Nicolino Milano (I876-I962); entre os mecenas sobressaem os irmãos Carlos (I883-I969) e Arnaldo Guinle (I884-I963). A atuação de outros mediadores, como Blaise Cendrars (I887-I96I), Jean Cocteau (I889-I963) e Paul Claudel (I868-I955), também é analisada, além da profícua atividade do dançarino, professor de dança, produtor e empresário brasileiro Duque, Antonio Lopes de Amorim Diniz (I884-I953). Esses intercâmbios baseavam-se em trocas culturais bem delimitadas possibilitadas por viagens, edições de partituras e gravação de discos que impulsionaram a circulação e a recepção da música brasileira na França através da crítica especializada e, sobretudo, através dos espetáculos.

Após a Primeira Guerra Mundial, uma nova dança brasileira desembarcou em Paris - o samba - e a popularidade veio com a turnê realizada pelos Oito Batutas ${ }^{6}$. A presença dos Oito Batutas nos palcos de Paris contribuiu muito para a introdução do samba no repertório francês, pois após o término da turnê seguiram-se as edições de partituras e discos. No entanto, embora a autora vá enfatizar a triangulação das

6 Os Oito Batutas foram um conjunto musical brasileiro criado em I9I9 no Rio de Janeiro e formado por Pixinguinha na flauta, Donga e Raul Palmieri no violão, Nelson Alves no cavaquinho, China no canto, violão e piano, José Alves no bandolim e ganzá e Luis de Oliveira na bandola e reco-reco. 
relações Estados Unidos, Brasil e França na segunda parte do livro, a presença dos Estados Unidos através do jazz já é marcante nesse período e influencia tanto a música brasileira e quanto a francesa. A dança de salão foi a principal modalidade de apropriação da música brasileira pela sociedade francesa nesse período. Por outro lado, o Brasil foi introduzido nas esferas da música erudita francesa, graças ao exotismo e ao primitivismo das figuras de Heitor Villa-Lobos e Darius Milhaud e, depois, ao desenvolvimento da etnografia musical.

Embora o leitor não vá encontrar uma análise musical aprofundada, ele terá uma ideia das apropriações que distanciaram la mattchiche e la samba feitos na França com seus correspondentes brasileiros: as partituras retiravam a maioria das síncopas7, sendo que somente a síncopa característica ${ }^{8}$ era uma constante na maioria das gravações francesas; a instrumentação era modificada, uma vez que o cavaquinho e o violão não participavam dos conjuntos musicais franceses; havia uma diminuição do andamento do maxixe; privilegiavam-se as versões instrumentais no samba e a redução dos dois gêneros ao aspecto rítmico.

A segunda parte do livro, O Sonho Exótico: I945-I959, em que há predominância do gosto típico, corresponde a período posterior à Segunda Guerra Mundial. Nessa época acontece uma nova difusão do samba e o surgimento do baião, gênero introduzido pelo sucesso do filme $O$ cangaceiro (Lima Barreto, I953, premiado em Cannes). As canções, com características brasileiras compostas na França, seja por franceses, seja por brasileiros ali residentes, ou, não raro, simples “adaptações” de músicas brasileiras atribuídas a compositores franceses, nesse período apresentavam uma versão muito simplificada da paisagem musical brasileira e associavam indiferentemente a Bahia e o Rio de Janeiro ao samba e ao baião. Como ressalta Fléchet, a dimensão regional do país, tão nevrálgica para uma percepção interna, escapava completamente aos músicos franceses. A simplificação e a mistura correspondiam nesse contexto às exigências da música típica, ligada à dança de salão. O samba francês, ou seja, o samba escrito por franceses, ou, ainda, a adaptação do samba brasileiro, apresentava um ritmo frenético e eliminava qualquer tristeza de sua letra. Assim, o profundo lamento do já citado samba que dá nome ao livro aqui tratado, "Madureira chorou”, foi, na versão "Si tu vas à Rio", transformado por Dario Moreno em "moças de cintura fina" que dançavam na "estrondosa alegria” das escolas de samba.

Durante a Segunda Guerra Mundial houve uma ruptura nos intercâmbios culturais entre o Brasil e a França. A retomada das circulações musicais pelo espaço Atlântico com o final da guerra, a partir de I945, tornou mais complexo o intercâmbio

7 Trata-se de um processo rítmico que desloca algumas notas para o tempo fraco do pulso regular da música, prolongando seu som sobre o tempo forte. A utilização da síncopa é fundamental nas músicas afro-americanas, como jazz, samba, maxixe, imprimindo o swing característico dessas produções. A síncopa existente na música ocidental europeia é uma exceção, um recurso composicional, "qualquer alteração deliberada do pulso ou métrica normal” (APEL apud SANDRONI, 200I, p. 2I), enquanto podemos notá-la como característica central nas músicas afro-americanas, o que é ouvido como exótico pelos músicos franceses que retiravam a maioria desses deslocamentos, acomodando muitas das notas nos tempos fortes do compasso, ou, grosso modo, "tocavam sem gingado".

8 Ver mais sobre a síncopa característica em: Andrade, I962; Sandroni, 200I. 
franco-brasileiro acrescentando-lhe uma nova dimensão, que gerou transferências culturais triangulares entre a França, os Estados Unidos e a América Latina e transformou as modalidades de apropriação dos ritmos brasileiros na França.

No pós-guerra, as inovações técnicas no domínio do disco e do rádio levaram a uma massificação sem precedentes da produção e do consumo musical. Na década de I950, o mercado de discos atinge um crescimento exponencial na França (de 3 milhões antes da guerra para 30 milhões em I958), e os aparelhos de rádio declarados eram Io milhões (I958). Assim o samba foi impulsionado como produto de massa. Naquele momento, as canções tradicionais francesas e árias de óperas eram arranjadas em estilo de samba. Em I948, a gravadora Polydor'9 apresentou a compilação Ça c'est la samba, com versões à maneira brasileira de "Frère Jacques", "Alouette, je te plumerai", entre outras; as orquestras latinas apropriaram-se do samba chamado de samba new look, importado via Estados Unidos, e surgiu o samba musette, cuja característica era a instrumentação: acordeão, clarineta ou saxofone, banjo, piano e percussão. Dos espetáculos de jazz, samba musette e music hall aos crooners românticos e big bands tropicais, o samba alimentou todos os gêneros mais populares na França nesse período, sem, no entanto, reproduzir o ritmo brasileiro, mas sendo definido como gênero musical híbrido associado a um forte imaginário exótico.

O baião, cuja formação típica era acordeão, triângulo e zabumba, conquistou o público francês. $\mathrm{O}$ baião francês era menos distante do baião brasileiro que o samba francês em relação ao samba brasileiro. O baião era menos estranho na esfera da sonoridade: seu ritmo sincopado não apresentava contrametricidade comparável à do samba, sendo mais fácil a identificação para um ouvido europeu. A proximidade da instrumentação e a menor complexidade rítmica permitiram aos músicos franceses se aproximarem mais comodamente desse gênero.

O desenvolvimento da etnomusicologia ${ }^{\mathrm{TO}}$ despertou um novo interesse pelas músicas tradicionais da América Latina na década de I950. Intelectuais franceses do pós-guerra interessavam-se pelo Brasil e, como objeto de estudo científico, o folclore brasileiro tornou-se igualmente um produto discográfico. Segundo os registros do depósito legal, foram distribuídos 40 discos de folclore brasileiro na França entre I945 e I959, a maioria registrada por artistas brasileiros em turnê pela Europa. A partir de I945, a música tradicional do Brasil suscitou um interesse sem precedentes na comunidade científica francesa, e o nacionalismo musical brasileiro, do qual Villa-Lobos continuou o principal representante até sua morte em I959, reforçou a difusão da música tradicional brasileira na cena musical francesa. Assim, o folclore e a música erudita contribuíram também nessa segunda etapa para diversificar

9 Bernard Hilda et Son Orchestre, Ça c'est la samba, Polydor, I948.

Io A etnomusicologia surgiu no final do século XIX e início do século XX, sob o nome de musicologia comparativa (Vergleichende Musikwissenschaft), sendo definida por Guido Adler (I885) como o ramo da musicologia que teria como tarefa a comparação das obras musicais, especialmente as canções folclóricas dos vários povos da terra, para propósitos etnográficos, e a classificação delas segundo suas várias formas. A mudança do nome é atribuída a Jaap Kunst, no seu livro Musicologia (I950), nessa época as pesquisas de campo têm grande impulso com as inovações técnicas concernentes aos equipamentos de gravação que possibilitaram o desenvolvimento da disciplina. 
o repertório brasileiro na França, dirigindo-se a públicos que não frequentavam necessariamente os bailes populares: amantes da música clássica, mas também intelectuais e acadêmicos.

A autora analisa ainda na segunda parte do estudo o imaginário criado a partir da paisagem sonora brasileira ${ }^{\mathrm{II}}$ : as canções brasileiras compostas na França após a Segunda Guerra Mundial baseavam-se com muita frequência na oposição binária entre o lá descrito de modo maravilhoso e o aqui feito de misérias e angústias. Outra mudança notada pela autora no pós-guerra: antes da Segunda Guerra a difusão da música brasileira na França era feita por homens, sendo raras as cantoras femininas, exceção feita a Elsie Houston ${ }^{\text {I2}}$; vozes francesas como Jacqueline François e Yvette Giraud surgiram no pós-guerra, e figuras como a brasileira Carmem Miranda e a italiana Silva Mangano foram decisivas para a difusão do samba e do baião, respectivamente.

A terceira parte do livro - Brasil, Nouvelle Vague - retrata uma época de ouro para o país no exterior: vencedor de três copas do mundo (I958, I962 e I970), o advento da capital Brasília (I960) e o sucesso do Cinema Novo (anos I960), a bossa nova (I962). A bossa nova havia sido introduzida na França pelo filme Orfeu negro (I959) - realizado pelo cineasta Marcel Camus (I9I2-I982), com roteiro de Vinicius de Moraes (I9I3-I980) e música original de Tom Jobim (I927-I994). O livro apresenta uma pormenorizada descrição da produção do filme, mas a autora ressalta que, embora o filme tenha sido um sucesso, a verdadeira difusão da bossa nova viria em I962, via Estados Unidos, uma vez que os álbuns produzidos nos Estados Unidos eram igualmente distribuídos em território francês graças aos acordos de licença firmados com empresas norte-americanas após a Segunda Guerra Mundial. Discos como Desafinado, de João Gilberto (I962), Jazz samba!, de Stan Getz e Charlie Byrd (I962), Getz/Gilberto (I964), gravado com João Gilberto, apogeu da bossa nova graças ao sucesso Garota de Ipanema, composição de Vinicius de Moraes e Tom Jobim, permitiram dissociar a bossa nova das práticas de dança de salão e abriram caminho para uma nova recepção da música popular brasileira na França.

A descoberta da bossa nova provocou uma reavaliação das modalidades de apropriação da música brasileira pelo público francês. Passando para o que a autora chama de gosto autêntico, pela primeira vez o público francês conheceu um gênero brasileiro que não se destinava à dança, mas à escuta, à maneira do jazz. Essa nouvelle vague propunha na realidade uma versão do gênero brasileiro com características modificadas, cujo principal vetor de difusão e de legitimação era o jazz. Apontamos algumas alterações na estética original da bossa nova pelos norte-americanos: o

II Conceito desenvolvido pelo canadense R. Murray Schafer (I933), a paisagem sonora é um conceito com origem na palavra inglesa soundscape, que se caracteriza pelo estudo e análise do universo sonoro que nos rodeia. Uma paisagem sonora é composta pelos diferentes sons que compõem determinado ambiente, sejam esses sons de origem natural, humana, industrial ou tecnológica.

I2 Soprano brasileira, pioneira na pesquisa e na difusão internacional das sonoridades do Brasil, Elsie Houston Péret (I902-I943) publicou Chants populaires du Brésil (I930) e La musique, la danse et les cérémonies populaires du Brésil (I93I). 
rompimento do intimismo do canto, substituído pelo improviso instrumental, e o privilégio do ritmo da bossa nova em detrimento de outros aspectos.

Os brasileiros eram agora considerados detentores de um conhecimento específico cuja transmissão era condição sine qua non para o desenvolvimento de uma linguagem musical autêntica, o tocar à brasileira, ou seja, transmitir a maneira de executar a música que era ouvida nos discos, algo intimamente ligado ao domínio da execução das síncopas tratadas no início desta resenha, ao gingado brasileiro. A autora destaca, nesse sentido, a valorização do violão brasileiro, seja nas capas dos discos que enfatizavam o lugar do instrumento na nova estética da música brasileira, seja nos primeiros métodos de ensino de música brasileira na França ou no aparecimento de professores especializados em ensinar o violão brasileiro a músicos amadores cujo número era estimado em I,2 milhão (I966). Nesse período, aumentou consideravelmente a exportação de violões brasileiros. Em I969 a fábrica Di Giorgio, de São Paulo, exportava mais de 2 mil instrumentos por mês para a Europa e os Estados Unidos.

Essa autenticidade diz respeito à proximidade do original, uma vez que seriam os próprios discos de músicos brasileiros e o trânsito de artistas brasileiros em turnês que começariam a servir de parâmetro para a recepção da música a partir dessa fase, segundo ressalta a própria autora, diferenciando a discussão sobre autenticidade em voga no Brasil no mesmo período, que se refere à crítica contra a incorporação de elementos estrangeiros à música brasileira. Nesse sentido, os franceses buscam professores de violão brasileiro e cruzam o Atlântico para conhecer como a música é executada por nossos músicos. Embora a autora evidencie essa evolução do gosto dos outros, ela mesma reforça que não se chega ao fim do exotismo com o autêntico, mas percebe-se um desenvolvimento das modalidades de apropriação da música brasileira pelos franceses ao longo do século XX.

A busca por autenticidade marcou uma mudança importante nos intercâmbios culturais: pela primeira vez artistas franceses empreenderam a travessia do Atlântico por razões estritamente ligadas à música. Para músicos como Pierre Barouh, Herbie Mann, Georges Moustaki, Sacha Distel ou para o crítico Gérard Merceron, a travessia do Atlântico adquirira uma dimensão iniciática e se tornara uma garantia de autenticidade que gravadoras, revistas e jornais transformavam em apelo comercial. No entanto, a substituição do típico pelo autêntico não significava necessariamente o fim do exotismo musical. Uma grande parte da música brasileira produzida na França continuava impregnada dos estereótipos elaborados ao longo dos períodos anteriores.

Porém, enquanto nos sambas do pós-guerra o exotismo era permeado pelo racismo, o lado africano da cultura brasileira tornou-se uma das maiores garantias de autenticidade a partir dos anos I960. A autora aponta o filme Orfeu negro como ponto de partida desse processo: pela primeira vez o Brasil era representado na tela por homens negros, a música associava-se agora ao povo negro do Brasil. Primeiramente no cinema, em filmes na linha do Orfeu negro e com a descoberta do Cinema Novo e posteriormente na televisão, onde músicos afro-brasileiros foram assuntos de várias reportagens nos anos I960 e I970, os ritmos brasileiros foram deixando a esfera das danças latinas e passaram nos anos de I960 e I970 ao campo das "músicas negras", como o jazz e o soul. 
Nessa última parte do livro, a autora trata ainda dos festivais organizados pelos dois países no fim dos anos I960, que desempenharam um papel importante na promoção dos ritmos brasileiros. Eles permitiram estabelecer contatos entre os produtores franceses e os músicos brasileiros, causando grande repercussão na França e possibilitando aos artistas franceses a descoberta do Brasil e da versão original de seus ritmos. São discutidas também as questões dos paradoxos da política cultural na ditadura brasileira no período da tropicália e da canção de protesto e suas correlações com as ondas de contestação de I968 na França.

Uma observação interessante é que nem todos os gêneros brasileiros atravessaram o Atlântico no mesmo ritmo, o que atesta os processos de seleção que sempre operam no seio das dinâmicas de transferências culturais. É o caso do choro, conforme nota a autora, gênero surgido na metade do século XIX, que permaneceu ignorado na França por muito tempo, emergindo como uma força no meio musical apenas no início dos anos 2000.

Embora seja possível verificar a magnitude da sua difusão, não é possível perceber qual o alcance da popularidade da música brasileira, se é restrita à classe social que consome e se envolve na produção de filmes, romances, livros, revistas e espetáculos, ou se se espraia de maneira mais ampla na sociedade francesa, mas não é este o escopo do livro, no entanto, nota-se que este poderia ser um dos muitos desdobramentos dessa pesquisa.

Longe de apresentar uma visão idealista ou estereotipada da cultura, a autora se mostra atenta às condições e contradições concretas das circulações musicais nos trânsitos apresentados. A comparação do contexto cultural francês com o brasileiro sugere dois importantes paralelismos: o desenvolvimento das indústrias musicais em cada lado do Atlântico e a elaboração de novos discursos sobre as culturas populares, dominados pela busca de exotismo na França e pela afirmação de uma identidade nacional no Brasil. Muito além de atingir apenas o público francês, o livro possibilita visualizar o impacto desses fenômenos na legitimação dos gêneros musicais populares na sociedade brasileira. Mais do que um estudo sobre as apropriações da música popular brasileira pelos artistas e o público francês, a autora nos permite examinar as práticas envolvidas nos intercâmbios entre os dois países e desafia a retórica de alteridade em que os ritmos brasileiros representariam sempre o exótico, o alheio, apresentando o desenvolvimento do gosto dos franceses pela música brasileira.

Essa publicação vem enriquecer a bibliografia da música brasileira, apresentando uma história original da recepção musical fora do Brasil, lançando novas luzes sobre a história transcultural da música brasileira. Ao cruzar diversas fontes não antes estudadas sobre a circulação da música e ao incluir a triangulação, estabelecida pela presença dos Estados Unidos nesse processo a partir dos anos I930, Anaïs Fléchet nos oferece uma visão externa de nossa história musical através de uma narrativa integrada, coerente e inédita. A autora disponibiliza, ainda, uma lista de partituras e gravações de música brasileira produzida e/ou distribuída na França e oito entrevistas realizadas para a pesquisa. Trata-se, portanto, de uma importante contribuição à historiografia da música brasileira, que certamente será referência para os estudos da área. 
SOBRE A AUTORA

FLAVIA REJANE PRANDO é violonista e doutoranda em Música pela Escola de Comunicações e Artes da Universidade de São Paulo (ECA/USP) e pesquisadora em Ciências Sociais e Humanas no Centro de Pesquisa e Formação do Serviço Social do Comércio (Sesc/SP). E-mail: flaviaprando@usp.br

\section{REFERÊNCIAS}

ANDRADE, Mário de. Ensaio sobre a música brasileira. São Paulo: Martins, I962.

SANDRONI, Carlos. Feitiço decente: transformações do samba no Rio de Janeiro (I9I7-I933). Rio de Janeiro: Jorge Zahar, 200I.

SCHAFER, R. Murray. A a finação do mundo. São Paulo: Unesp, 20oI. 